\title{
10 Gbps Five Levels Polibinary Signaling for Short Range and Access Networks
}

\author{
Vegas Olmos, Juan José; Suhr, L. F.; Li, Bomin; Tafur Monroy, Idelfonso
}

Published in:

ACP/IPOC 2013

Publication date:

2013

Document Version

Publisher's PDF, also known as Version of record

Link back to DTU Orbit

Citation (APA):

Vegas Olmos, J. J., Suhr, L. F., Li, B., \& Tafur Monroy, I. (2013). 10 Gbps Five Levels Polibinary Signaling for Short Range and Access Networks. In ACP/IPOC 2013 [AW4G.3] Optical Society of America.

\section{General rights}

Copyright and moral rights for the publications made accessible in the public portal are retained by the authors and/or other copyright owners and it is a condition of accessing publications that users recognise and abide by the legal requirements associated with these rights.

- Users may download and print one copy of any publication from the public portal for the purpose of private study or research.

- You may not further distribute the material or use it for any profit-making activity or commercial gain

- You may freely distribute the URL identifying the publication in the public portal

If you believe that this document breaches copyright please contact us providing details, and we will remove access to the work immediately and investigate your claim 


\title{
10 Gbps Five Levels Polibinary Signaling for Short Range and Access Networks
}

\author{
J.J. Vegas Olmos, L.F. Suhr, B. Li, and I. Tafur Monroy \\ Department of Photonics Engineering, Technical University of Denmark, Ørsted Plads 343, Kgs. Lyngby, 2800, Denmark \\ jjvo@fotonik.dtu.dk
}

\begin{abstract}
This paper presents a novel five level polibinary signaling modulation and experimentally demonstrates $10 \mathrm{Gbit} / \mathrm{s}$ generation and transmission up to $20 \mathrm{Km}$ utilizing only $1.8 \mathrm{GHz}$ bandwidth.

OCIS codes: (060.4510) Optical Communications; (060.4080) Modulation.
\end{abstract}

\section{Introduction}

Increasing capacity in optical channels is forcing technology to move from spectral inefficient non-return to zero (NRZ) to advanced modulation formats. Moreover, the complexity raise in the transmitter and receiver must be kept to the minimum in order to maintain the cost contained. There are two main scenarios that require high capacity with low complexity, short reach optical interconnects [1] and optical access networks [2]. These scenarios are currently requiring $400 \mathrm{G}$ and $40-100 \mathrm{G}$ solutions, respectively. Different techniques have been used for advanced modulation, such as discrete multitone (DMT) [3], carrierless amplitude/phase (CAP) [4], orthogonal frequency division multiplexing (OFDM) [3], and N-pulse amplitude modulation (N-PAM) [6]. Additionally, duobinary modulation has been extensively used in high-capacity backplanes [7], where the roll-off of the backplane itself matches the spectrum profile of the duobinary signal. Duobinary modulation is in fact a part of the family of polibinary signaling presenting three levels. Polibinary signals can actually have as many as M levels, as early identified [8-10]. A polibinary signal with five levels, $M=5$, presents a competitive advantage in terms of bandwidth usage: theoretically a bit rate of $\mathrm{B}$ can be sustained in a channel of single-sided bandwidth $\mathrm{B} / 8$ of the original bandwidth. The advantages of a five level polibinary signal stemming from a reduced bandwidth when considering transmission are very attractive: chromatic dispersion impairments are drastically reduced, along with stimulated Brillouin backscattering (SBS), which infers higher launch power into the fiber can be sustained.

In this paper we provide a proof-of-concept of polibinary signaling at $9.1 \mathrm{Gbps}(10 \mathrm{G}$ class) with five levels using only $1.8 \mathrm{GHz}$ of bandwidth, which effectively provides a spectral efficiency of $5.05 \mathrm{~b} / \mathrm{Hz} / \mathrm{s}$. Polibinary signaling of high order provides a technical solution to overcome bandlimited optical transmitters and receivers, and paves the way to bring multigigabit capacity to end users cost-effectively. To the best of our knowledge, no experimental assessment of optical five level polibinary has been reported before at any bitrate.

\section{Background and experimental demonstration}

Polibinary signaling is an advanced modulation format, also known as partial-response transmission format, which makes use of bit correlation to reduce the spectral width. This correlation is introduced through an amount of controlled Inter-Symbol Interference (ISI). This controlled ISI is introduced by a simple codification scheme [10] in which each output bit is modulo-2 of the previous three output bits and the current bit. By using this specific coding, not only ISI is introduced but also degeneracy in the recovery is avoided. Degeneracy would occur in an uncoded polibinary signal if the receiver provides a wrongful output which is later taken as an element to figure out further bits. Once the coding is conducted, a low pass filter (LPF) is generally used to remove the undesired frequency components. There have been many research efforts to optimize the LPF's bandwidth in duobinary systems [11-12]. As a rule of thumb, it is well known that for a duobinary signaling, fifth order low pass Bessel filters having a $3 \mathrm{~dB}$ bandwidth equal to the quarter of the data rate gives a satisfactory performance. For a five level polibinary, and based on sound assumptions, the bandwidth of the Bessel filter must be in the order of 1.8-2 GHz.

The receiver side using polibinary can be based on simple standard direct-detection (DD), and then either sampled and the signal recovered using digital signal processing (DSP) or by placing analog thresholds. Either approach is employed, the complexity is in the vicinity of 4-PAM and 8-PAM receivers, which are currently considered viable solutions for $100 / 400 \mathrm{G}$ solutions [13]. DSP processing offers the advantage of flexibility and reconfigurability on the spot, and because the bandwidth of the polibinary signal is extremely reduced in comparison to the original NRZ, the pressure on the processing power at the receiver is reduced drastically. 

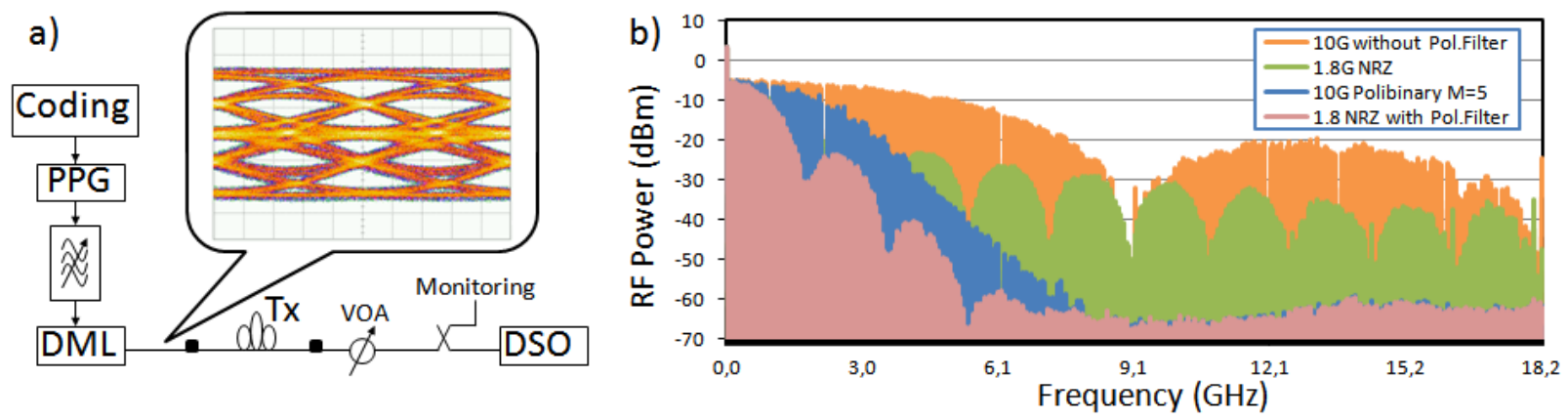

Fig. 1. Experimental setup (a) and electrical spectrum of different signals after optical generation (b). PPG: pulse pattern generator. DML: directly modulated laser. Tx: transmission link. VOA: variable optical attenuator. DSO. Digital sampling oscilloscope.

Figure 1(a) shows the experimental setup employed to demonstrate five level polibinary modulation and an inset of the eye diagram back-to-back five level polibinary signal. The setup consisted of a pulse pattern generator (PPG) loaded with the precoded five level polibinary bit stream. The signal from the PPF was strongly filtered by a $5^{\text {th }}$ order Bessel filter with a $1.8 \mathrm{GHz}$ frequency cut-off and then used to modulate a directly modulated laser (DML) operating at $1550.2 \mathrm{~nm}$. The optical polibinary signal was then transmitted through different fiber spans, and sampled and stored by a digital sampling oscilloscope with $13 \mathrm{GHz}$ bandwidth at 40 Gsamples. Fig.1(b) the electrical spectrum of different optical signals to benchmark the spectra utilization of the five level polibinary signal. As it can be observed, the $10 \mathrm{Gbps} \mathrm{NRZ}$ and the $1.8 \mathrm{Gbps}$ signals present lobules occupying $10 \mathrm{GHz}$ and $1.8 \mathrm{GHz}$, respectively. These measurements were then completed by adding the Bessel filter; the filtering allows transferring the first three lobules of the $1.8 \mathrm{Gbps} \mathrm{NRZ}$ signal, which at practical effects does not impact its shape. However, when a five level polibinary $10 \mathrm{Gbps}$ is generated, we can observe the spectra is severely reduce and contained within the first $2 \mathrm{GHz}$.
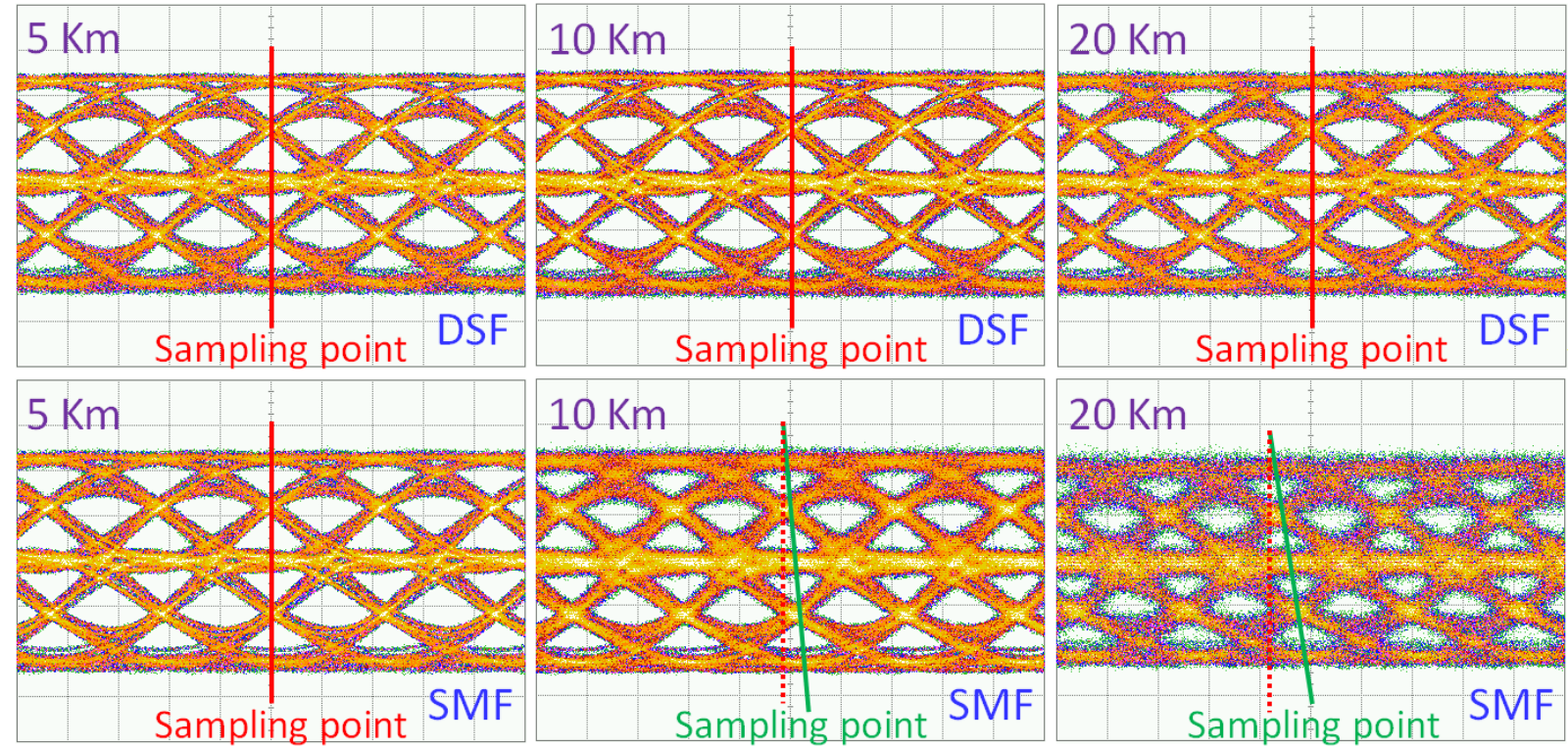

Fig. 2. Eye diagram of the back-to-back five level polibinary signal and the eyes diagrams after transmission through different length spans of DSF and SMF. Due to dispersion, the eye diagram skews after transmission in SMF beyond $10 \mathrm{Km}$.

Figure 2 shows the eye diagram after transmission through different length spans, specifically 5-, 10- and 20 $\mathrm{Km}$. The fibers were chosen to be dispersion shifted fiber (DSF) and single mode fiber (SMF), which are arguably the most commonly deployed types of fiber. As it can be observed, the eye diagrams after 5-, 10- and $20 \mathrm{Km}$ of DSF remain faithful to the back-to-back (Fig.1(a)). Due to dispersion, SMF shows a skewing of the eye diagram after 10and $20-\mathrm{Km}$, which forces the DSP to adjust the sampling point. This effect can be therefore overcome although it inherently impairs the signal. The dispersion effect is clearly observable in the bit error rate (BER) curves, which are presented in Figure 3. The BER curves were measured for 10- and 20-Km, as we expected an identical performance of the $5 \mathrm{Km}$ transmission. As it can be observed, DSF transmission and SMF of $10 \mathrm{Km}$ produce BER with an 
identical performance as the back-to-back case, whereas transmission through $20 \mathrm{Km}$ of SMF incurs in a $2 \mathrm{~dB}$ power penalty.

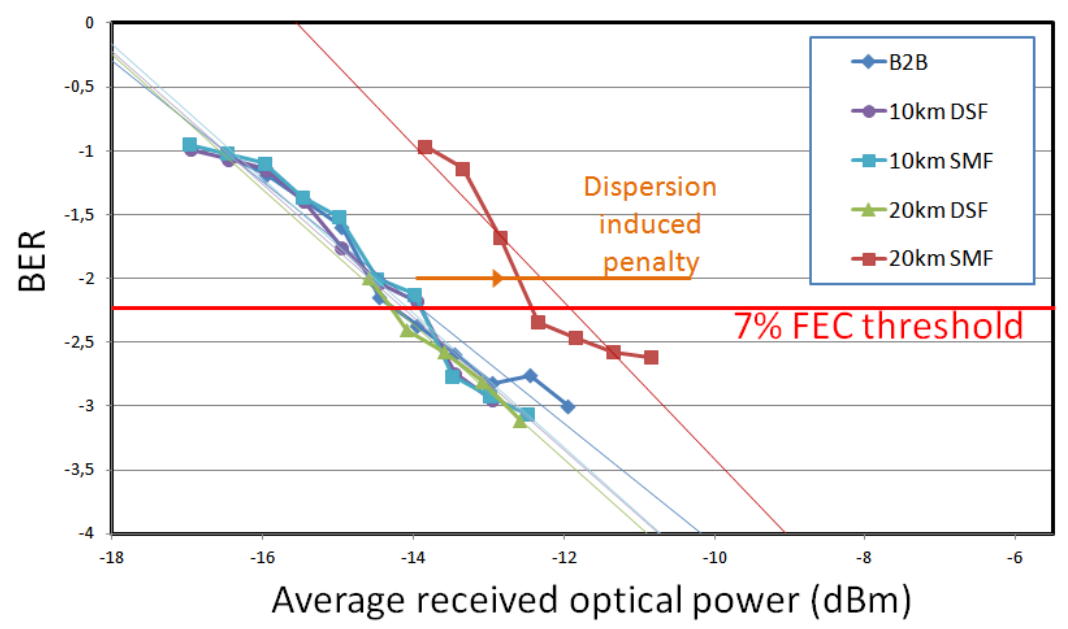

Fig. 3. Bit error rate (BER) performance of the five level $10 \mathrm{Gbps}$ polibinary signal after different transmission links.

\section{Conclusions}

In this paper, we present a five level polibinary signaling for high-capacity optical access networks and short range systems. We experimentally demonstrated a polibinary signaling at $10 \mathrm{Gbit} / \mathrm{s}$ using only $1.8 \mathrm{GHz}$ of bandwidth, which effectively provides a spectral efficiency of $5.5 \mathrm{bit} / \mathrm{s} / \mathrm{Hz}$. The complexity of the transmitter, compared to regular NRZ systems, lies in the need of precoding the signal and placing a low pass band filter. However, the savings in terms of bandwidth is more than fourfold when compared to regular NRZ signaling. Therefore, polibinary signaling of fifth order, provides a technical solution to overcome band limited optical transmitters and receivers with a contained complexity, and paves the way to bring multigigabit capacity to end users cost-effectively. Similarly, short-range systems for interconnects and data centers, which require high-capacity and requirements on optical signal to noise ratio (OSNR) are not as strict as in long transmission links, polibinary signaling can enable the way to simple $100 \mathrm{G} / 400 \mathrm{G}$ communications.

\section{References}

[1] IEEE $802.3400 \mathrm{~Gb} / \mathrm{s}$ Ethernet Study Group, http://www.ieee802.org/3/400GSG/public/13_05/index.shtml

[2] Y. Luo et al., "Time- and Wavelength-Division Multiplexed Passive Optical Network (TWDM-PON) for Next-Generation PON Stage 2 (NG-PON2)," J. Lightwave Technol. 31, 587-593 (2013)

[3] T. Tanaka et al., "50Gbps class transmission in single mode fiber using discrete multi-tone modulation with $10 \mathrm{G}$ directly modulated laser," OSA Optical Fiber Communication Conference, paper OTh4G (2012).

[4] M. Iglesias Olmedo et al., "Towards 400GBASE 4-lane solution using direct detection of multicap signal in 14GHz bandwidth per lane," OSA Optical Fiber Communication Conference, Postdeadline Session III, paper PDP5C (2013).

[5] R.P. Giddings, E. Hugues-Salas, and J.M. Tang, "ExExperimental demonstration of record high 19.125Gb/s real-time end-to-end dual-band optical OFDM transmission over 25km SMF in a simple EML-based IMDD system," Opt. Express 20, 20666-20679 (2012)

[6] S. Bhoja, "Study of PAM modulation for 100GE over a single fiber," IEEE Next Gen 100G Optical Ethernet Study Group (2012) http://www.ieee802.org/3/100GNGOPTX/public/jan12/bhoja_01_0112_NG100GOPTX.pdf

[7] J.H. Sinsky, A. Adamiecki, and M. Duelk, "10-Gb/s electrical backplane transmission using duobinary signaling," 2004 IEEE MTT-S International Microwave Symposium Digest (1), 109-112 (2004).

[8] A. Lender, "Correlative digital communication techniques," IEEE Trans. on Communication Technology, 128-135 (1964)

[9] R. Howson, "An analysis of the capabilities of polybinary data transmission," IEEE Trans. on Comm. Tech. 13, 312-319 (1965).

[10] S. Walklin et al., "Multilevel signaling for increasing the reach of $10 \mathrm{~Gb} / \mathrm{s}$ lightwave systems," J. Light. Tech. 17, 2235-2248 (1999).

[11] Y. C. Lu et al., " $2.5 \mathrm{~dB}$ Sensitivity Improvement by Optimizing the Driving Voltage of an MZM and Electrical Filter Bandwidth of Optical Duobinary Transmission Systems," in Optical Fiber Communication Conference, Optical Society of America, paper JThB42 (2006) http://www.opticsinfobase.org/abstract.cfm?URI=NFOEC-2006-JThB42

[12]I. Lyubomirsky, and C. C. Chien, "Ideal duobinary generating filter for optically amplified systems", IEEE Photon. Technol. Lett.18 (4), pp. 598-600 (2006)

[13]D. Brown, "NRZ vs. PAM-N for $400 \mathrm{GbE}$ in the data center," Ethernet Technology Summit.

\section{Acknowledgements}

The authors would like to thank J.M. Estaran for fruitful discussions on the topics of advanced modulation formats and digital signal processing. J.J. Vegas Olmos acknowledges the Marie Curie program for partly funding this research through the WISCON project. 